\title{
Está na pauta deliberar? Uma análise da deliberação sobre a maioridade penal na Folha de S. Paulo
}

\author{
Is on the agenda to deliberate? An analysis of the deliberation on the criminal \\ age in the newspaper Folha de S. Paulo
}

\section{Está en la agenda deliberar? Una analisis de la deliberación sobre la edad penal en el periódico Folha de S. Paulo}

\author{
Paulo Ferracioli $^{1}$ \\ Carla Rizzotto ${ }^{2}$
}

\begin{abstract}
Resumo
Os meios de comunicação possuem uma função vital para a democracia contemporânea pois se caracterizam como um fórum de debate cívico. Com o intuito de descobrir se os meios de comunicação de massa conseguem servir como espaços deliberativos adequados, são analisadas 19 matérias relativas ao tema da maioridade penal da Folha de S. Paulo, publicadas ao longo de 45 dias em 2015. Para tanto são utilizadas as categorias propostas por Maia (2008) para investigar a deliberação: acessibilidade; identificação e caracterização dos interlocutores; utilização de argumentos; reciprocidade e responsividade; reflexividade e revisibilidade de opiniões. Entre as conclusões, destaca-se uma predominância de fontes oficiais para a discussão de temas. Ainda, não houve espaço para que aspectos como a reciprocidade e a revisibilidade de opiniões pudessem ocorrer a contento.
\end{abstract}

\begin{tabular}{|c|c|}
\hline & Acesse este artigo online \\
\hline \multirow{2}{*}{ 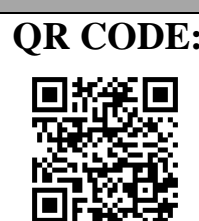 } & $\begin{array}{l}\text { Website: } \\
\text { http://www.revistas.ufg.br/index.php/ci }\end{array}$ \\
\hline & $\begin{array}{l}\text { DOI: } \\
\text { http://dx.doi.org/10.5216/ci.v20i1.39813 }\end{array}$ \\
\hline
\end{tabular}

Palavras-chave: Deliberação. Maioridade Penal. Folha de S. Paulo.

\begin{abstract}
The media plays a vital role in contemporary democracy since is characterized as a civic deliberative forum. In order to find out whether the mass media can serve as suitable deliberative space, this article analyses 19 news relating to the issue of criminal age responsibility of the newspaper Folha de S. Paulo published over 45 days in 2015. For this purpose are used the categories proposed by Maia (2008) to investigate the deliberation: accessibility; identification and characterization of interlocutors; use of arguments; reciprocity and responsiveness; reflexivity and revisibility of opinions. Among the findings, there is a predominance of official sources for the discussion. Still, there was no room for reciprocity and revisibility of views to take place satisfactorily.
\end{abstract}

Keywords: Deliberation. Criminal Age. Folha de S. Paulo.

1 Mestre em Comunicação pela UFPR. Doutorando do Programa de Pós-Graduação em Ciência Política da mesma instituição. Brasil, Paraná, Curitiba. E-mail: ferracioli.paulo@gmail.com

2 Doutora em Comunicação, professora do PPGCom/UFPR. Bolsista PNPD/Capes. Brasil, Paraná, Curitiba. E-mail: carla_rizzotto@yahoo.com.br 


\section{Resumen}

Los medios de comunicación tienen un papel vital en la democracia contemporánea, pues caracterizanse como un foro para el debate cívico. Con el fin de averiguar si los medios de comunicación pueden servir como espacios deliberativos adecuados, se analizan 19 noticias de la Folha de S. Paulo relativas a la cuestión de la responsabilidad penal publicado durante 45 días en el año 2015. Para ello se utilizan las categorías propuestas por Maia (2008) para investigar la deliberación: la accesibilidad; identificación y caracterización de los interlocutores; utilización de argumentos; la reciprocidad y la capacidad de respuesta; reflexividad y revisibilidad de opiniones. Entre los resultados, hay un predominio de las fuentes oficiales para la discusión de los temas. También, no hay espacio para que la reciprocidad y la revisibilidad de puntos de vista puedan ocurrir de manera satisfactoria.

Palabras-clave: Deliberación. Responsabilidad penal. Folha de S. Paulo.

\section{INTRODUÇÃO}

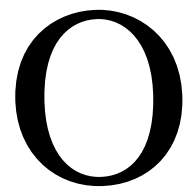

s meios de comunicação, além das funções de entretenimento e informação, possuem uma função vital para a democracia contemporânea: dão destaque a temas públicos relevantes, que são discutidos perante toda a sociedade.

Esse suporte prevê a relação entre a mídia e a política, se tomarmos como política as relações entre os grupos e os indivíduos para construção e modificação das regras que regem a sociedade (MAIA, 2008). E os meios de comunicação de massa desempenham um papel que não pode ser subestimado nessa luta simbólica entre os discursos. Eles são um fórum de debate cívico, que constroem uma arena de debates que chamam os atores sociais a participar e expressar seus pontos de vista e a qual todos os cidadãos podem assistir (MAIA, 2008).

A partir dessa concepção, o presente artigo busca compreender de que forma os meios de comunicação podem ser um fórum eficiente para a democracia deliberativa, conceito proposto pelos cientistas políticos e que vem sendo bastante estudado. A intenção é descobrir como certas questões ganham relevância, de que maneira elas são abordadas e constroem sentido, além de descobrir quais os atores que são autorizados a participar desse processo.

Dentre os inúmeros temas polêmicos e que mobilizam debates em todas as classes sociais, um dos que chama a atenção é a redução da maioridade penal. Há grande clamor popular para que as normas atuais sejam revistas, especialmente após tragédias que envolvem adolescentes e ganham repercussão nacional na mídia, ainda que seja quase consenso entre os estudiosos da questão de que essa não é a medida mais eficaz. Em razão dessa oposição ferrenha, é interessante entender como os meios de comunicação abordam e desenvolvem essa temática. 
A análise aqui pretendida é devedora de um campo que recebe atenção na comunicação política, dedicado a se aprofundar nas implicações entre a mídia, a esfera pública e os processos de deliberação.

\title{
2 DELIBERAÇÃO E OS MEIOS DE COMUNICAÇÃO
}

A democracia deliberativa é uma compreensão discursiva da democracia que pode ser definida da seguinte maneira:

\begin{abstract}
uma forma de governo, na qual cidadãos livres e iguais (e seus representantes) justificam decisões em um processo no qual eles dão uns aos outros argumentos que são mutuamente aceitáveis e acessíveis por todos, com o objetivo de alcançar conclusões que são obrigatórias no presente para todos os cidadãos mas estão abertas a serem transformadas no futuro (GUTMANN, THOMPSON, 2004, p. 7, tradução nossa).
\end{abstract}

Esse conceito deixa claro alguns aspectos importantes da deliberação. O primeiro diz respeito à importância conferida aos cidadãos. Não se pode considerá-los como meros seres a afetados pelas leis produzidas e decisões tomadas, mas como agentes com autonomia para interferir no processo democrático e compreender os motivos do que está sendo discutido (GUTMANN; THOMPSON, 2004).

É preciso levar em conta também que a deliberação precisa ser acessível aos cidadãos, sob dois aspectos principais: as discussões devem ser públicas, ou seja, de acesso a todos, bem como os conteúdos e argumentos precisam ser entendidos pela população (GUTMANN; THOMPSON, 2004). A deliberação permite que a participação política ocorra através do intercâmbio de argumentos, sem que seja preciso envolvimento direto nas decisões (MAIA, 2008).

Ainda, a deliberação não exige um resultado imediato, mas compreende a valorização da reflexão, da explicação dos interesses dos grupos, da ponderação sobre as consequências das possíveis decisões e da descoberta das "soluções possíveis" (MAIA, 2008).

Essa concepção de democracia põe ênfase no caráter comunicativo da política, ao visualizar a tomada de decisões como consequência de trocas de argumentos relevantes nos mais variados espaços. É uma maneira de garantir que a legitimidade do poder político se dará através da justificação pública, cabendo aos indivíduos raciocinar com base nos argumentos apresentados e tirar suas conclusões em um processo de comunicação que ocorra da maneira mais livre possível (MAIA, 2008). 


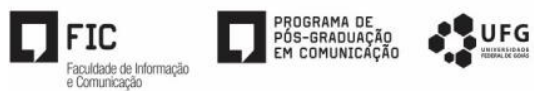

Para atingir o maior número possível de cidadãos em seus fóruns, os processos deliberativos precisam ocorrer em ambientes com capacidade de penetração em todos os segmentos da sociedade. O principal espaço para isso ainda é representado pela mídia e os meios de comunicação.

Na esfera pública, os problemas da coletividade são apresentados e, mais do que isso, debatidos pela sociedade. Não basta apenas apontá-los, pois:

a esfera pública tem que reforçar a pressão exercida pelos problemas, ou seja, ela não pode limitar-se a percebê-los e a identificá-los, devendo, além disso, tematizá-los, problematizá-los e dramatizá-los de modo convincente e eficaz, a ponto de serem assumidos e elaborados pelo complexo parlamentar (HABERMAS, 1997, p. 91).

$\mathrm{Na}$ atualidade, há uma ligação profunda entre a mídia e a esfera pública. Ainda que "os meios de comunicação não possam ser entendidos como uma 'esfera pública' em si, eles disponibilizam expressões, matérias, discursos, eventos para o conhecimento comum" (MAIA, 2008, p. 18). Dito de outro modo, a mídia não é a esfera pública, mas permite que a esfera se desenvolva através de um diálogo público generalizado.

Assim, a mídia é um dos canais através do qual a esfera pública se propõe a fazer a discussão dos problemas políticos. Os meios de comunicação são elementos essenciais nesse processo, porque não há outro fórum que possua tamanho alcance e repercussão (MAIA, 2008). Alguns aspectos da deliberação que parecem irrealizáveis entre inúmeros participantes podem ser minimizados pelos meios de comunicação. A inclusividade, por exemplo, pode ser alcançada através dos argumentos apresentados por vários lados, ainda que não estejam todos os cidadãos face a face discutindo a questão (MARQUES, 2008). A imprensa e sua cobertura sobre questões públicas pode evitar que a conversação generalizada seja rasa ou que a deliberação seja restrita a especialistas e não se torne acessível ao grande público (GOMES, 2007).

Essa importância crucial levou Habermas a denominar os meios de comunicação de "esfera pública abstrata", uma vez que transportam os processos comunicativos típicos das interações face-a-face ou em pequenos grupos para uma audiência muito mais ampla e nãosimultânea, seja de leitores ou espectadores (MAIA, 2008).

Nessa compreensão sobre a importância dos meios para a deliberação, cabe lembrar que os meios não são canais neutros, que apenas transmitem informações de maneira imparcial, mas são também atores do campos político, econômico etc. Assim, é impossível 
dissociar sua atuação como agente e sua produção de conteúdo, tendo em vista que as relações por vezes conflitantes que eles estabelecem com grupos, é influenciada por essas questões (MAIA, 2008).

É preciso dar o destaque para os jornalistas e outros profissionais de comunicação, que são os responsáveis por criar essa arena, através da seleção de tópicos abordados, pessoas que serão ouvidas e qual o destaque que cada assunto terá. Os atores que têm acesso aos canais de mídia o conseguem em decorrência do capital de que dispõem e de como influenciam os responsáveis pelos meios de comunicação, que detêm o poder de determinar quais vozes se destacarão nos fluxos da esfera pública (HABERMAS, 2006).

Em suma, os meios de comunicação podem ser apontados como atores importantes no processo deliberativo. Em sociedades populosas, os jornalistas cumprem melhor a tarefa de disseminar as informações para o maior número de pessoas. Dessa forma, "mediated deliberation can be highly public and successful, but only if decentralization produces a variety of opinions and the division of political labor is capable of producing suficient cognitive diversity and mutual criticism "(PAGE, 1995, apud BOHMAN, 1998, p. 421).

Todo o posicionamento criado pela mídia não pode ser reduzido a uma visão dicotômica entre a favor ou contra, mas a partir das nuances que uma análise de enquadramento pode fornecer. O jornalismo não pode ser visto nem sob uma ótica liberal idealizada, que crê numa promoção perfeita de valores, mas também não pode ser demonizado, sob pena de que não se encontre saídas viáveis para o jornalismo no atual sistema capitalista (SOARES, 2009).

O entendimento sobre o alcance da deliberação através dos meios de comunicação é um tema que precisa ser pesquisado, a fim de entender as nuances e características desse processo.

\section{PROCEDIMENTOS METODOLÓGICOS}

Para realizar uma análise do caráter deliberativo dos meios de comunicação, Maia (2008) aponta cinco aspectos que podem ser identificados: acessibilidade; identificação e caracterização dos interlocutores; utilização de argumentos; reciprocidade e responsividade; reflexividade e revisibilidade de opiniões.

Essa estratificação se baseia na proposta de Bennett (2004), que propôs um estudo sobre a deliberação midiática a partir de três qualidades definidoras: o acesso (quem participa 
do discurso da mídia), do reconhecimento (como são identificados os atores que participam do processo) e da responsividade (estabelecimento de diálogo entre os atores com posições opostas)

Em busca de um objeto empírico adequado para essa investigação sobre os cinco aspectos, foi escolhido o tema da redução da maioridade penal. Esse tópico não é objeto de consenso entre os cidadãos e ganhou visibilidade em meados de 2015, quando a Câmara aprovou em primeiro turno mudança na Constituição que permite que jovens de 16 anos sejam punidos por alguns crimes (tais como o homicídio qualificado) da mesma maneira que adultos.

O jornal impresso, que busca sua sobrevivência trazendo discussões embasadas, no aprofundamento dos conteúdos que a Internet tende a apenas resvalar, parece ser um ambiente ideal para o desenvolvimento da deliberação. No caso brasileiro, o jornal de maior circulação nacional é a Folha de S. Paulo, considerado um "qualitypaper", lido por ampla parcela da classe média e alta, em especial aqueles que se convencionou chamar de "formadores de opinião".

O acervo digital do periódico, que permite acesso a reproduções online do jornal impresso de maneira idêntica àquela quando foi veiculado, foi consultado a partir do termo "maioridade penal". O período inicial para os textos coletados foi $1^{\circ}$ de junho de 2015 , tendo em vista que o presidente da Câmara Eduardo Cunha anunciara em seu perfil do Twitter na véspera que colocaria o projeto em discussão na casa legislativa. A data limite estabelecida foi dia 17 de julho de 2015, quando teve início o recesso parlamentar e a consequente paralisação momentânea das discussões no âmbito institucional.

Foram desconsideradas notas curtas, que mal chegam a três linhas e costumeiramente apresentadas na coluna Painel, e também os artigos de opinião e editoriais. Feita essa seleção, foram encontradas 19 matérias, que serão analisadas a seguir.

Importante destacar, inicialmente, que todas essas matérias foram veiculadas na editoria "Cotidiano", que se assemelha ao que pode ser classificado como editoria geral do jornal, e não na editoria "Poder", que é a seção da Folha de S. Paulo que cobre os temas políticos.

\section{ANÁLISE E DISCUSSÃO DOS RESULTADOS}


Os cinco aspectos sugeridos por Maia permitiram que fossem criadas categorias, nas quais cada texto foi enquadrado, que serão discutidas individualmente.

\subsection{Acessibilidade}

As fontes que são ouvidas em uma matéria não são escolhidas ao acaso, ocorrendo, na maioria das vezes, uma reprodução das desigualdades de poder que existem na sociedade (MAIA, 2008). Tendo em mente que ter acesso ao meio de comunicação é uma das medidas chave do poder nas democracias modernas (BENNETT, ENTMAN, 2001), importante identificar quais os grupos que apareceram na cobertura noticiosa.

A acessibilidade foi analisada a partir dos grupos a que pertenciam os agentes que ganhavam voz nos textos. As seguintes categorias foram criadas: 1- membros do Poder Executivo; 2 - deputados e senadores; 3 - professores universitários e especialistas, 4 membros do Judiciário e Ministério Público; 5 - vítimas de crimes, 6 - ONGs.

A análise revelou o seguinte resultado:

Gráfico 1 - Acessibilidade
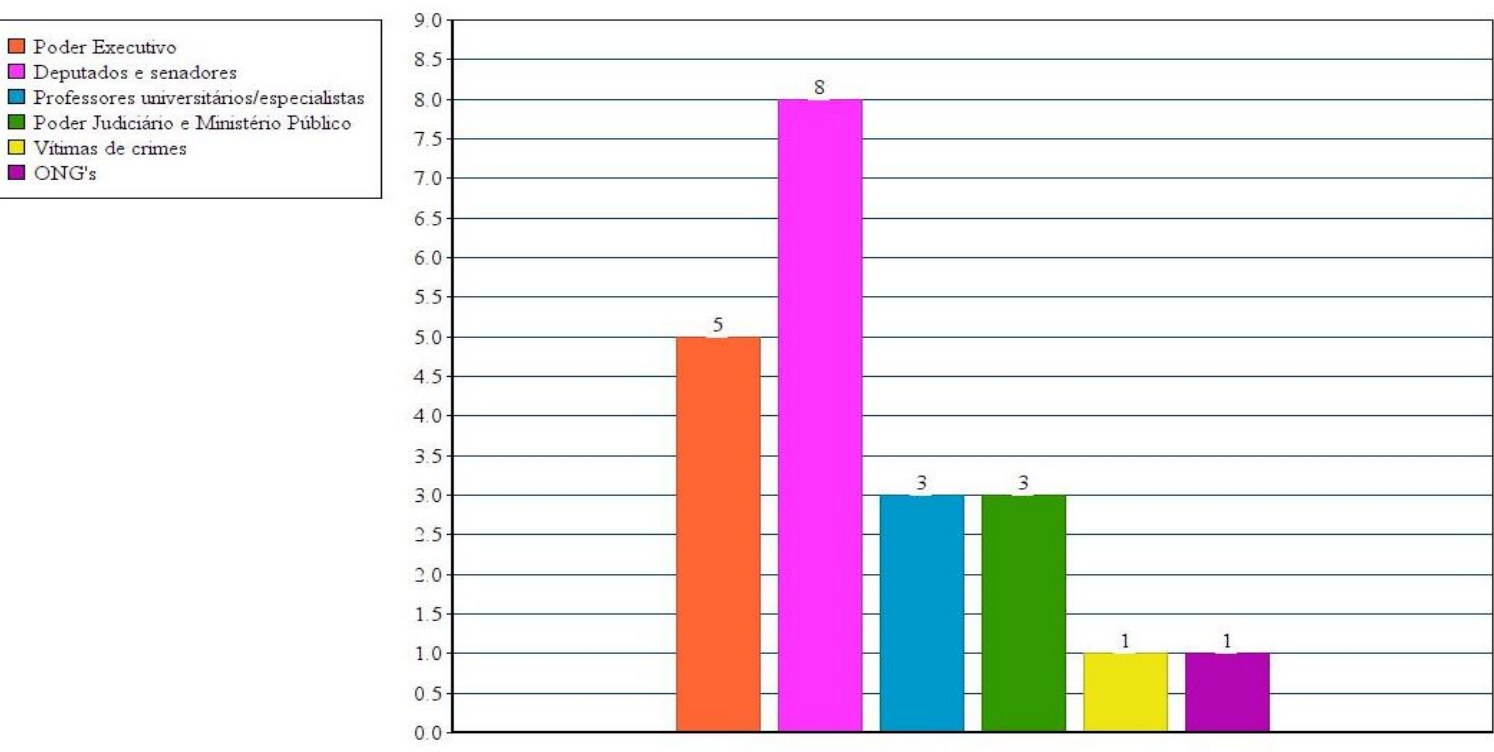

Fonte: elaborado pelos autores

Como é possível observar, os deputados e senadores foram os agentes que mais tiveram espaço para expressar seus pensamentos sobre a questão da maioridade penal. Ainda que os projetos estivessem em debate no Congresso, há uma disparidade imensa entre o 


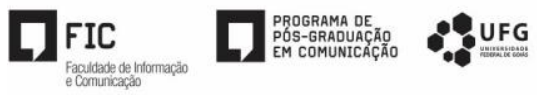

número de vezes em que foram ouvidos e o número de vezes em que foi concedido espaço para participantes de ONGs, por exemplo.

Muitas das falas dos deputados vinham de pronunciamentos na rede social Twitter, como ocorria frequentemente com o presidente da Câmara Eduardo Cunha. A primeira reportagem sobre o assunto saiu em função de um tweet do parlamentar e essa era a única manifestação dele, uma vez que não foi feita entrevista com o congressista.

Uma ONG que desenvolve atividades com menores infratores foi ouvida em apenas uma matéria, o que indica a falta de espaço para a sociedade civil se pronunciar. As diversas matérias em nenhum momento buscaram trazer a voz de algum menor infrator, ou de alguém que tenha sido penalizado e pudesse dar sua experiência. Faltou assim uma preocupação em dar autonomia no debate para grupos diretamente relacionados ao tema, o que é essencial para uma boa prática deliberativa (GUTMANN; THOMPSON, 2004).

Os discursos autorizados a se pronunciar se restringiram a fontes oficiais, se englobarmos autoridades do Executivo, Judiciário e Legislativo. Os outros atores foram praticamente desconsiderados pelas reportagens.

\subsection{Identificação e caracterização dos interlocutores}

Esse critério busca "identificar os papeis institucionais definidos dos atores e o universo de expectativas a eles associadas" (MAIA, 2008). A intenção é descobrir a maneira como os atores que têm acesso ao debate são trazidos para a deliberação.

Para analisar esse critério, foi utilizada uma análise qualitativa da maneira como as fontes e personagens foram chamados a expressar seus argumentos.

Uma das indagações era descobrir se os jornalistas já rotulavam os indivíduos de defensores ou de opositores à mudança constitucional. A pesquisa demonstrou que a quase totalidade das matérias não demarcou os interlocutores como membros de um lado ou outro, optando por uma construção mais sutil. Assim, a regra é que houvesse apenas uma descrição da profissão ocupada pelo entrevistado (quase sempre uma autoridade, como visto no tópico anterior).

Em apenas uma matéria, a mãe de um jovem que foi morto por um adolescente em um assalto em São Paulo já é identificada como defensora da redução da maioridade penal, antes mesmo de que fosse aberto espaço para sua fala com seus argumentos. 


\subsection{Utilização de Argumentos}

As discussões midiáticas ocorrem através de "lances discursivos" (MAIA, 2008), ou seja, dificilmente há um longo argumento desenvolvido, mas diversas posições são apresentadas em pequenas porções ao longo da cobertura.

No caso em análise, os argumentos levantados pelo jornal em suas matérias foram classificados conforme tabela proposta por Maia et al (2015) em artigo que discutia a deliberação sobre a maioridade penal (Tabela 1).

Tabela 1 - Lista de argumentos 
ARGUMENTOS A FAVOR DA REDUÇÃO DA MAIORIDADE PENAL

\begin{tabular}{c|l}
\hline ARGUMENTO & \multicolumn{1}{c}{ DESCRIÇÃO } \\
\hline $\mathbf{A}$ & $\begin{array}{l}\text { O número de atos infracionais cometidos por adolescentes está aumentando, por } \\
\text { isso é preciso que eles respondam criminalmente, o que resultará na diminuição da } \\
\text { violência } \\
\text { A responsabilização prevista atualmente par a adolescentes que cometem atos } \\
\text { infracionais graves é fraca/branda porque o ECA não é adequado à realidade atual } \\
\text { e, por isso, é preciso reduzir a mai oridade penal }\end{array}$ \\
\hline $\mathbf{C}$ & $\begin{array}{l}\text { Os adolescentes, a partir dos 16 anos, já são capazes de saber o que é certo e errado } \\
\text { e, por isso, deve-se reduzir a idade penal }\end{array}$ \\
\hline $\mathbf{D}$ & $\begin{array}{l}\text { Se os adolescentes aos 16 anos os têm inúmeros direitos, eles devem responder } \\
\text { criminalmente por seus atos infracionais. Em vários paises a idade penal é abaixo } \\
\text { dos 18 anos }\end{array}$ \\
\hline $\mathbf{E}$ & $\begin{array}{l}\text { Os adolescentes se envolvem em atos infracionais porque sabem da impunidade } \\
\text { A redução da mai oridade tem amplo apoio popular e reduzir a idade penal satisfaz a } \\
\text { vontade da maioria. } \\
\text { Deve haver redução da maioridade penal, mas politicas públicas precisam ser } \\
\text { desenvolvidas para aperfeiçoar o sistema carcerário para receber adolescentes }\end{array}$ \\
\hline G
\end{tabular}

ARGUMENTOS CONTRÁRIOS À REDUÇÃO DA MAIORIDADE PENAL

\begin{tabular}{c|l} 
ARGUMENTO & \multicolumn{1}{c}{ DESCRIC ÃO } \\
\hline $\mathbf{H}$ & $\begin{array}{l}\text { Educar é mais eficiente do que punir, sendo mais eficaz investir em politicas } \\
\text { públicas para evitar que adol escentes se envolvam em atos infracionais }\end{array}$ \\
\hline $\mathbf{I l}$ & $\begin{array}{l}\text { Encaminhar adol escentes que cometem atos infracionais para a prisão os coloca em } \\
\text { contato com uma realidade violenta, que acaba por aumentar as práticas } \\
\text { infracionais, ao invés de diminui-las. }\end{array}$ \\
\hline $\mathbf{I 2}$ & $\begin{array}{l}\text { Encaminhar adol escentes que cometem atos infracionais para a prisão irá complicar } \\
\text { ainda mais o sistema carcerário que está superlotado }\end{array}$ \\
\hline $\mathbf{K}$ & $\begin{array}{l}\text { A maioria dos atos infracionais é de menor gravidade e, por, isso reduzir aidade } \\
\text { penal não resolverá o problema da viole ência }\end{array}$ \\
\hline $\mathbf{L}$ & $\begin{array}{l}\text { Grupos criminosos irão cooptar crianças e adol escentes cada vez mais novos, caso a } \\
\text { maioridade penal seja reduzida. Por isso, reduzir a maioridade não soluciona o } \\
\text { problema da violência }\end{array}$ \\
\hline $\mathbf{M}$ & $\begin{array}{l}\text { Os adolescentes de classe baixa serão mais prejudicados porque os de classe média } \\
\text { e alta não costumam ser responsabilizados. A maioria dos adolescentes que } \\
\text { cometem atos infracionais vem de situações de pobreza e de familias } \\
\text { desestruturadas. É um problema social, não de criminalidade } \\
\text { A maioridade penal aos 18 anos é cláusul a pétrea. Ė um compromisso internacional }\end{array}$ \\
\hline $\mathbf{N 1}$ & $\begin{array}{l}\text { As medidas socioeducativas aplicadas a adolescentes que cometem atos } \\
\text { infracionais são suficientes enquanto forma de responsabilização, portanto, basta } \\
\text { cumprir a lei; }\end{array}$ \\
\hline $\mathbf{N 2}$ & $\begin{array}{l}\text { As medidas socioeducativas aplicadas a adolescentes que cometem atos } \\
\text { infracionais são suficientes enquanto forma de responsabilização, mas é preciso } \\
\text { corrigir e aperfeiçoar o sistema socioeducativo }\end{array}$ \\
\hline $\mathbf{O}$ & $\begin{array}{l}\text { Adol escentes são sujeitos em condição de desenvolvimento e, portanto, não se deve } \\
\text { reduzir a mai oridade penal }\end{array}$
\end{tabular}

Fonte: Grupo EME/UFMG 


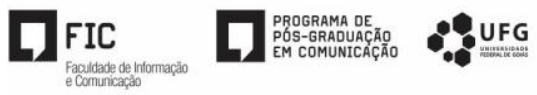

Um dado que chama a atenção é que 7 matérias, das 19 analisadas, não traziam nenhum desses argumentos. Algumas matérias focavam na possível aprovação da PEC ou nos trâmites legislativos que possibilitaram (ou não) a sua aprovação um dia depois de ser rejeitada, sem dar espaço para discussão sobre o conteúdo da proposta. São textos que revelam uma cobertura da política com um viés ganha-perde, pensada como um jogo de tabuleiro, disputas entre governo e oposição cujas motivações dificilmente eram analisadas.

No entanto, foi possível identificar uma exceção mesmo em uma das matérias que não trazia argumentos para deliberação. Esse texto envolvia apenas a discussão sobre os dados de cumprimento de medida socioeducativa por adolescentes, que quase todos os estados não disponibilizam. Ainda que fosse uma matéria bem apurada, ela não se centrava em discutir a viabilidade ou não da redução, mas apenas a ausência de informações empíricas sobre o tema. É uma característica do jornalismo praticado pela Folha de S. Paulo, que preza muito o embasamento com dados e estatísticas.

Outros argumentos propostos por Maia et al (2015) na tabela nem chegaram a aparecer nas matérias. Foi o caso do argumento L, que se centra no impacto da redução para as classes mais pobres, identificando a questão sob o lado social. Embora essa justificativa seja frequente nas discussões pessoais e nas redes sociais, ela não apareceu nas reportagens.

Se for feita uma comparação entre a frequência dos motivos favoráveis e contrários à maioridade penal aos 16 anos, se chega à conclusão de que os argumentos a favor da redução aparecem 17 vezes, enquanto as justificativas contrárias surgiram 24 vezes nas matérias da Folha de S. Paulo, conforme demonstra o gráfico 2 abaixo.

Gráfico 2 - Argumentos utilizados

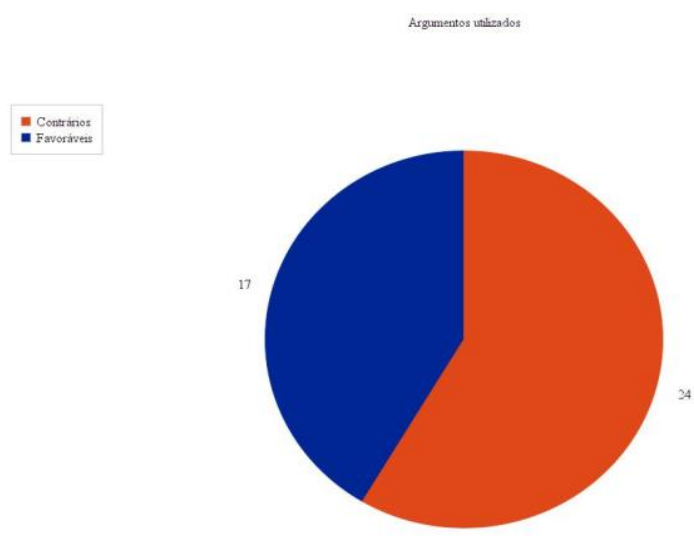

Fonte: elaborado pelos autores 
Tendo como base esses argumentos, que praticamente exploram na totalidade as razões possíveis para a defesa de um lado ou de outro da disputa, foi possível contabilizar quais e quantos argumentos apareceram na publicação.

O resultado está exposto nos gráficos 3 e 4 a seguir, sendo que o eixo das abcissas representam os argumentos utilizados (na classificação já detalhada na tabela previamente apresentada), enquanto o eixo das ordenadas indica a frequência em que tais razões surgiram nas matérias da Folha:

Gráfico 3 - Argumentos a favor da redução da maioridade penal

Argumentos a favor da redução da maioridade penal

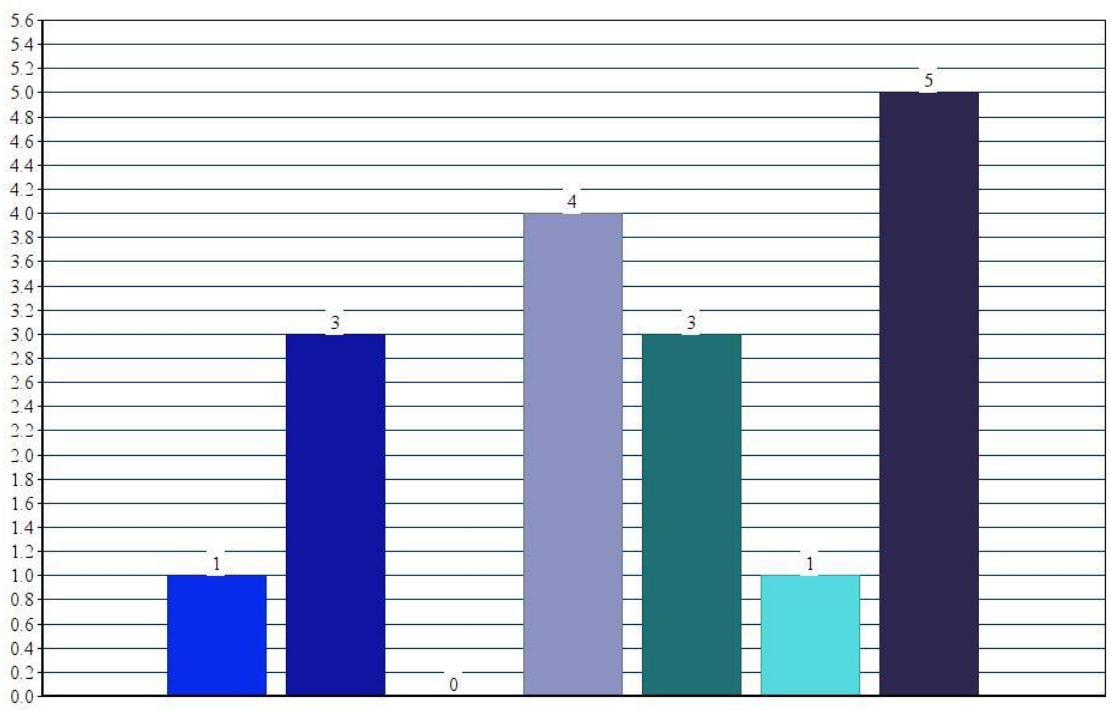

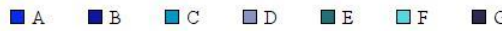

Fonte: elaborado pelos autores 
Gráfico 4 - Argumentos contrários à redução da maioridade penal Argumentos contránios à reduçăo da maioridade penal
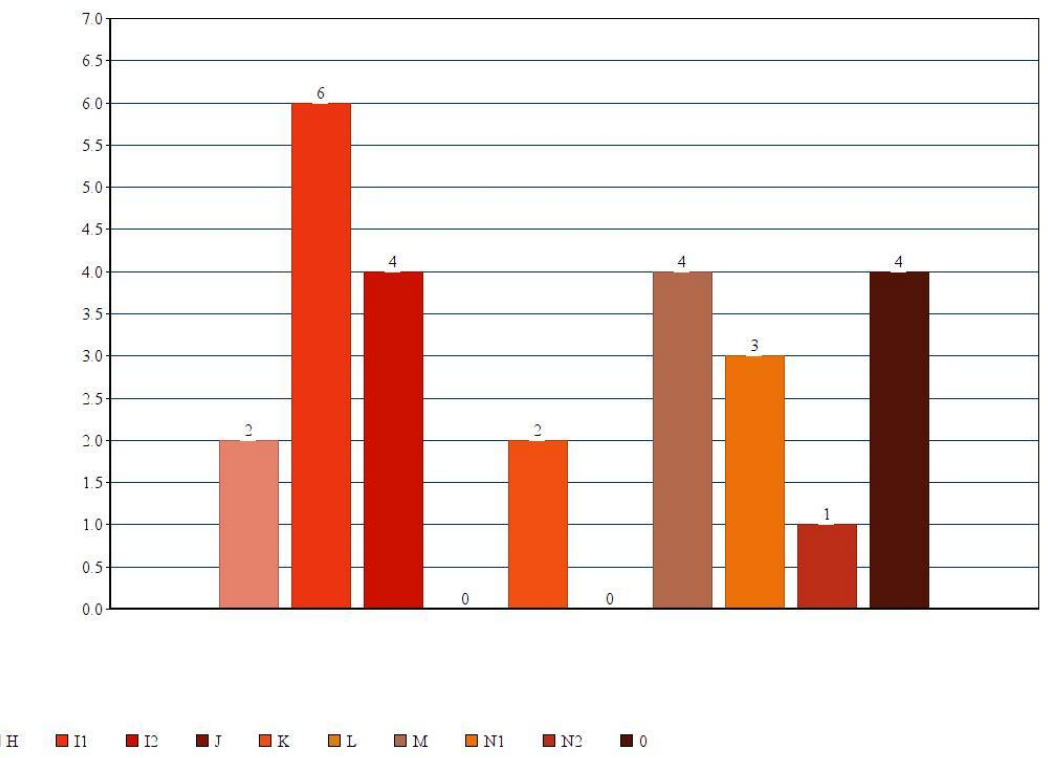

Fonte: elaborado pelos autores

$\mathrm{O}$ argumento mais frequente, presente em 6 matérias, é o "il”, que pontua que a redução da maioridade colocará os jovens em contato com uma realidade mais violenta, o que levará ao aumento da criminalidade. Isso é dito, por exemplo, na matéria do dia 18 de junho, quando um infográfico que reúne os argumentos aponta que "jovens seriam alvo de facções criminosas ao serem presos com adultos".

Logo em seguida, com 5 aparições, constou o argumento G, que é favorável à redução da criminalidade, mas aponta a necessidade de reformular as políticas públicas para lidar com essa eventual alteração legal. Esse discurso apareceu, predominantemente, da seguinte maneira: “após a mudança na Constituição, poderiam ser construídos presídios para os jovens de 16 a 18 anos condenados por crimes", também na reportagem do dia 18/06/2015. Nota-se que este é um argumento favorável à redução que já prevê que a mera mudança não é suficiente, de modo que sua aparição recorrente mostra a adoção de uma visão mais conciliadora por parte dos defensores da maioridade penal aos 16 anos.

Os argumentos com menor frequência nas matérias analisadas correspondem às letras $\mathrm{A}, \mathrm{F}$ e $\mathrm{n} 2$, que representam, respectivamente, o aumento dos atos infracionais por adolescentes, o amplo apoio popular da redução e a necessidade de aperfeiçoamento das atuais medidas socioeducativas, sem que seja preciso a alteração na idade. 
Dentre esses, chama a atenção o fato de que a preferência popular pela redução da maioridade, constatada até mesmo pelo instituto de pesquisa do mesmo grupo do periódico, não tenha sido apresentada mais vezes. Sua única menção foi no dia 18 de junho, sob a rubrica "resposta à população", quando é dito que "pesquisas mostram que a maior parte da população é favorável à redução da maioridade penal. Mudança corresponderia ao anseio popular".

Ademais, foi possível notar que os argumentos apareciam sempre em blocos, como nas matérias dos dias 18 e 22 de junho e $1^{\circ}$ de julho. Em cada uma dessas, constam pelo menos sete argumentos. Isso é resultado da opção editorial em apresentar essas razões através de tabelas, opondo os lados do "sim" e do "não", às vezes com mais de seis aspectos de cada um, que motivaram as decisões.

\subsection{Reciprocidade e Responsividade}

A reciprocidade ou responsividade, caracterizado pelo processo em que os atores oferecem respostas a questões formuladas pelos seus oponentes, é essencial para a deliberação. Tal prática, no entanto, pode ser prejudicada quando os interlocutores estão presos nas suas posições e não desenvolvem um diálogo (MAIA, 2008).

Esse tópico merece uma análise qualitativa a partir das 19 matérias analisadas. Essa relação de conversa entre as fontes das matérias não ocorreu, muito porque a maioria das matérias mostrava os argumentos em tabelas, um embaixo do outro, sem que houvesse qualquer relação estabelecida entre eles. Não havia textos escritos de maneira que os argumentos se relacionassem um com os outros, apontando os pontos falhos de cada e suas justificativas.

O máximo de conversa que era estabelecido entre os argumentos dispostos nos infográficos era colocar um argumento contrário e um favorável lado a lado. Assim, por exemplo, o argumento para apoiar a redução de letra "D", que alega que os jovens de 16 já têm direitos como votar, era posto ao lado do argumento "O", que alega que os adolescentes ainda estão em processo de formação moral e intelectual.

A única matéria que permitiu uma reciprocidade maior entre os argumentos foi publicada no dia 12 de julho, em página dupla. Essa extensão maior permitiu que fossem veiculadas entrevistas com dois desembargadores com visões opostas sobre a redução. Foi 
口

através das perguntas do repórter que os pensamentos de cada lado puderam ser melhor desenvolvidos.

Por exemplo, o desembargador que respondeu que a violência não tem a ver com pobreza, mas com índole, foi logo questionado se não haveria nenhuma implicação de fatores sociais no cometimento de atos ilícitos por menores. Esse embate entre entrevistador e entrevistado foi o único caminho para que as ideias pudessem ser rebatidas e reconstruídas.

Não se descarta a possibilidade de que a responsividade pudesse estar presente na relação entre uma matéria e outra, mas dentro de cada texto noticioso não foi possível perceber a construção do diálogo almejada por esse critério (MAIA, 2008).

\subsection{Reflexividade e Revisibilidade de Opiniões}

A troca de argumentos ao longo do processo deliberativo permite que os atores alterem suas posições. A partir das perspectivas oferecidas pelo debate, é possível que os indivíduos proponham novas visões, adequadas aos discursos que estão em conflito (MAIA, 2008).

Para analisar a cobertura da maioridade penal, a reflexividade foi identificada quando algum dos falantes mostrava que havia revisto seu posicionamento depois de conversa com outro grupo.

O resultado da análise foi o seguinte (Gráfico 5): 
Gráfico 5 - Reflexividade e Revisibilidade de Opiniões

Reflexividade e Revisibilidade de Opiniōes

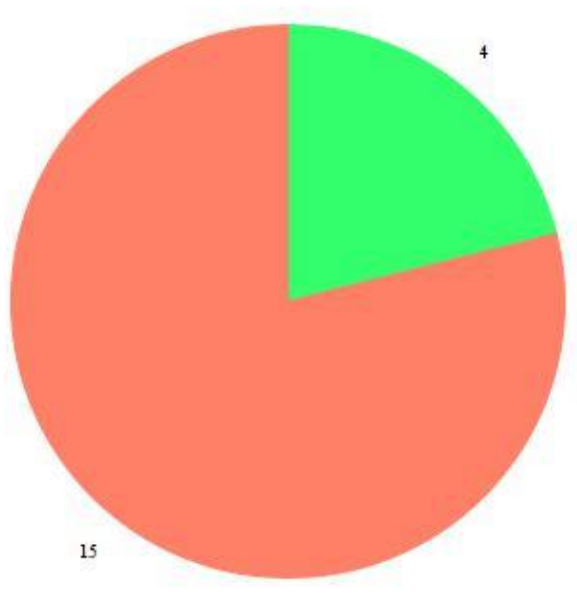

Nim Não

Fonte: elaborado pelos autores

As poucas matérias (apenas 4) que puderam ser identificadas como contendo revisibilidade foram aquelas em que houve notícias sobre mudanças de posicionamento de parlamentares, que estariam dispostos a votar um projeto que aumentasse o tempo de internação em lugar da proposta que reduz a maioridade penal.

Essas notícias, de abordagem quase resumida às conversas partidárias, foram as únicas que demonstraram haver troca de argumentos entre os envolvidos, com mudança de posições. A maioria das matérias, no entanto, passou longe de qualquer demonstração de revisão de opiniões, se resumindo a exposição dos pontos de vista e dos trâmites legislativos.

\section{CONSIDERAÇÕES FINAIS}

A mídia pode se constituir um terreno fértil para a deliberação. Em sociedades complexas, em que é fisicamente inviável reunir a todos para discutir, são os meios de comunicação que apresentam potencial para propiciar um campo para o debate entre todos os grupos envolvidos. 
A análise desenvolvida no presente artigo, no entanto, mostrou que o jornalismo ainda peca em construir uma deliberação integral e, porque não dizer, mais eficiente. As fontes ouvidas são sempre as mesmas e raramente fogem do círculo tradicional, com preferências para detentores de cargos políticos. Ouvir personagens que realmente estão envolvidos no problema não é a tônica do noticiário. Nem mesmo cidadãos comuns, que sentem a violência nos eu cotidiano, tiveram alguma opinião colhida.

A diversidade de argumentos também não foi a ideal, uma vez que certas justificativas eram apresentadas em todas as matérias e outras nunca chegaram a ser veiculadas. Isso conflita com a abordagem de que o jornal, preocupado com o processo democrático, deve fornecer as razões disponíveis para que o leitor possa formar a opinião própria. Um estudo futuro poderia investigar o porquê de certas justificativas não terem conseguido ao menos aparecer nas páginas do jornal.

Os aspectos da reciprocidade e revisibilidade foram os menos presentes na cobertura da redução da maioridade penal pelo jornal. A falta de textos que opusessem as ideias, de maneira encadeada, empobrece o jogo deliberativo. A cobertura passa apenas a agrupar os argumentos dos dois lados, sem que haja um debate qualificado entre as visões.

A mídia tem potencial para promover fóruns ideias para a efetivação da deliberação, mas ainda se está longe de classificar o cenário atual como satisfatório. Um jornalismo sofisticado e empenhado com a construção democrática precisa abrir espaço para a esfera deliberativa, com provimento de razões diversas provenientes de fontes de várias camadas sociais, de forma a efetivar uma troca argumentativa real, em que haja reciprocidade e responsividade entre os grupos. É através de uma mídia preocupada com a qualidade desse processo que a deliberação pode ganhar protagonismo e incrementar nosso sistema democrático.

\section{REFERÊNCIAS}

BENNETT, W. Lance; ENTMAN, Robert (eds). Mediated politics. Cambridge: Cambridge University Press, 2001.

BENNETT, Lance et al. Managing public sphere: journalistic construction of the great globalization debate. Journal of Communication, Oxford, n. 3, p. 437-454, set. 2004. BOHMAN, The coming of age of deliberative democracy.The journal of political philosphy, v. 6, n. 4, p. 400-425, 1998. 
ETTEMA, James S. Journalism as Reason-Giving: deliberative democracy, institutional accountability, and the news-media's mission. Political Communication, v. 24, p. 143-160, 2007.

GOMES, Wilson. Publicidade, visibilidade, discutibilidade: para uma revisão do conceito de esfera pública política. In: ENCONTRO ANUAL DA COMPÓS, 16., 2007, Curitiba. Anais... Curitiba, 2007.

GUTMANN, Amy; THOMPSON, Dennis. Why deliberative democracy? Princeton: Princeton University Press, 2004.

HABERMAS, Jürgen. Direito e democracia: entre facticidade e validade, v. II. Rio de Janeiro: Tempo Brasileiro, 1997.

- Political communication in media society: does democracy still enjoy anepistemic dimension? The impact of normative theory on empirical research.Communication Theory, v.16, p. 411-426, 2006.

MAIA, Rousiley C. M. (Coord). Mídia e deliberação. Rio de Janeiro: Editora FGV, 2008.

MAIA, Rousiley C. M. et al. Conversação e Deliberação sobre questões sensíveis: um estudo sobre o uso das razões que circulam nos media. Trabalho apresentado no GT Comunicação e Política da XXIV Compós, 2015.

MARQUES, Angela Cristina Salgueiro. Os meios de comunicação na esfera pública: novas perspectivas para as articulações entre diferentes arenas e atores. Líbero, ano XI, n. 21, 2008

SOARES, Murilo Cesar. Representações, jornalismo e a esfera pública democrática. São Paulo: Cultura Acadêmica, 2009. 